\title{
Experimental investigation on effect of different shaped steel fibers on compressive strength of high strength concrete
}

\author{
D.B.Mohite ${ }^{1}$, S.B.Shinde ${ }^{2}$ \\ ${ }^{1}$ PG student of civil engg. Department, Jawaharlal Nehru Engg. College Aurangabad MS, India \\ ${ }^{2}$ Asso.Proffesor and Head of civil engg. Department, Jawaharlal Nehru Engg.College Aurangabad MS, India
}

\begin{abstract}
This paper presents the results of the experimental investigation of various strengths of steel fiber reinforced concrete (SFRC). Variables considered in the research work of various shapes and fiber volume fractions. Compressive strength is investigated using mix of M70 grade and hooked, flat and waved fibers with aspect ratio 50. The fiber volume fraction is varied from $0.5 \%$ to $4 \%$ at an interval of $0.5 \%$ by weight of cement separately. Standard test specimens for compressive strengths were cast and water cured for 7 and 28 days. All the test specimens were tested according to relevant Indian Standards and standard test procedures available in the literature wherever applicable. Compressive strengths are found to be increased continuously with increase in fiber volume fraction.
\end{abstract}

Keywords: composites, SFRC, aspect ratio, fiber volume fraction, strengths

\section{Introduction}

Plain cement concrete is the most widely used material for construction of various structures. However, it suffers from numerous drawbacks such as, low tensile strength, brittleness, unstable crack propagation and low fracture resistance etc. Addition of steel fibers to plain cement concrete results in improved structural properties, such as better resistance against cracking, impact, thermal shocks, wear, fatigue, spalling and improved compressive, flexural, tensile, shear, bond strengths, ductility and toughness. Hence, steel fiber reinforced concrete (SFRC) has been proved as a reliable and promising composite construction material having superior performance characteristics compared to conventional concrete.

\section{Literature Review}

A compressive review of literature related to fiber reinforced concrete is presented by Balaguru and Shah [1] and Beaudoin [2] including guidelines for design, mixing, placing and finishing steel fiber reinforced concrete. Hannant [3] has presented the basic theoretical and simplified principles of FRC subjected to various states of stress. The improvement in various strengths of SFRC has been studied by various research workers with low fiber volume fractions of fibers [4 - 12]. Crimped fibers, surfaces deformed fibers and fibers with end anchorage have shown to produce more strength than that is given by smooth fibers for the same volume content. Recently Ghugal [13] has studied the structural behavior of glass fiber reinforced concrete using mathematical models. In this paper effect of hooked, flat, waveing fibers on properties of hardened concrete with high volume fractions are studied. The results of an investigation carried out on compressive strength of hardened concrete are presented.

\section{Experimental Program}

Ordinary Portland cement of 53 grade confirming to IS 12269 and natural sand and coarse aggregates $(10,20 \mathrm{~mm})$ confirming to IS 8112 and IS 383 and hooked, flat, waveing steel fibers were used. The cement and aggregates were tested to fulfil the IS requirements. The fineness moduli of fine and coarse aggregates were 3.2 and 7.7 respectively. The hooked, flat, waveing steel fibres having tensile strength $825 \mathrm{MPa}$, modulus of elasticity $200 \mathrm{GPa}$ and aspect ratio 50 were used. The M-70 grade of concrete having mix proportions developed by using DOE method was used throughout the experimental investigation. The concrete ingredients, namely, cement, fine, coarse aggregates and fibers were first mixed in the dry state and water was added last. Cubes of $100 \mathrm{~mm}$ size for compressive test were casted incorporating $0.0 \%$ to $4.0 \%$ hooked, flat, waveing steel fibers at the interval of $0.5 \%$ by weight of cement seperately. For each test, three specimens were cast with and without fibers. Compaction of all the specimens was done using table vibrator to avoid balling of fibers. All the specimens were water cured for 28 days at room temperature and were tested in surface dry condition on 1000 $\mathrm{kN}$ Universal Testing Machine. In all 150 specimens were cast and tested to evaluate the strengths performance. Each value of the results presented in this is the average of three test samples. 


\section{Discussion Of Test Results}

The tests on hardened concrete are carried out according to the relevant standards wherever applicable. Results obtained using experiments, theory and proposed expressions are presented and discussed in comparison with those of normal concrete.

\section{Compressive Strength:}

This strength was determined by carrying out cube compressive test on $150 \mathrm{~mm}$ size cubes, using UTM. Compressive strength results of SFRC compared to that of normal concrete $(\mathrm{Vf}=0.0 \%)$ are shown in below Table 1, Table 2, Table 3

Table 1: Compressive strength of SFRC, MPa. (Waving Shape Fiber)

\begin{tabular}{|c|c|c|c|c|}
\hline \multirow{2}{*}{$\begin{array}{c}\text { Fibre Content } \\
(V f) \%\end{array}$} & \multicolumn{3}{|c|}{$\begin{array}{c}\text { Compressive Strength (MPa) } \\
\text { Strength }\end{array}$} \\
\cline { 2 - 5 } & 7 days & 28 days & 7 days & 28 days \\
\hline 0 & 50.35 & 76.3 & - & - \\
\hline 0.5 & 52.14 & 79 & 3.5 & 3.53 \\
\hline 1 & 53.23 & 80.86 & 5.71 & 5.97 \\
\hline 1.5 & 54.02 & 81.26 & 7.28 & 6.5 \\
\hline 2 & 54.68 & 82 & 8.59 & 7.47 \\
\hline 2.5 & 54.86 & 82.93 & 8.95 & 8.68 \\
\hline 3 & 57.09 & 85.5 & 13.38 & 12.05 \\
\hline 3.5 & 57.83 & 86.63 & 14.85 & 13.53 \\
\hline 4 & 58.34 & 87.4 & 15.86 & 14.54 \\
\hline
\end{tabular}

The compressive strength increased continuously with the increase in the fiber content. The increase in the strength is directly proportional to the fiber content. The maximum increase in compressive strength at $4.0 \%$ of fiber content is $14.54 \%$ at 28 days.

Table 2: Compressive strength of SFRC, MPa. (Flat Shaped Fiber)

\begin{tabular}{|c|c|c|c|c|}
\hline \multirow{2}{*}{$\begin{array}{c}\text { Fibre Content } \\
(V f) \%\end{array}$} & \multicolumn{2}{|c|}{ Compressive Strength (MPa) } & \multicolumn{2}{c|}{$\begin{array}{c}\text { increase in Compressive } \\
\text { Strength }\end{array}$} \\
\cline { 2 - 5 } & 7 days & 28 days & 7 days & 28 days \\
\hline 0 & 50.35 & 76.3 & - & - \\
\hline 0.5 & 50.82 & 76.8 & 0.9 & 0.65 \\
\hline 1 & 51.81 & 77.5 & 2.89 & 1.57 \\
\hline 1.5 & 53.13 & 79.5 & 5.52 & 4.19 \\
\hline 2 & 54.12 & 81 & 7.48 & 6.15 \\
\hline 2.5 & 57.09 & 84.5 & 13.38 & 10.74 \\
\hline 3 & 57.55 & 86.2 & 14.29 & 12.87 \\
\hline 3.5 & 58.08 & 87.2 & 15.35 & 14.28 \\
\hline 4 & 58.67 & 88.3 & 16.52 & 15.72 \\
\hline
\end{tabular}

The compressive strength increased continuously with the increase in the fiber content. The increase in the strength is directly proportional to the fiber content. The maximum increase in compressive strength at $4.0 \%$ of fiber content is $15.72 \%$ at 28 days.

Table 3: Compressive strength of SFRC, MPa. (Hooked Shaped Fiber)

\begin{tabular}{|c|c|c|c|c|}
\hline \multirow{2}{*}{$\begin{array}{c}\text { Fibre Content } \\
(V f) \%\end{array}$} & \multicolumn{2}{|c|}{ Compressive Strength (MPa) } & \multicolumn{2}{c|}{$\begin{array}{c}\text { increase in Compressive } \\
\text { Strength }\end{array}$} \\
\cline { 2 - 5 } & 7 days & 28 days & 7 days & 28 days \\
\hline 0 & 50.35 & 76.3 & - & - \\
\hline 0.5 & 51.15 & 76.9 & 1.58 & 0.78 \\
\hline 1 & 51.48 & 77.5 & 2.24 & 1.57 \\
\hline 1.5 & 52.27 & 78.5 & 3.18 & 2.49 \\
\hline
\end{tabular}




\begin{tabular}{|c|c|c|c|c|}
2 & 52.8 & 79 & 4.86 & 4.19 \\
\hline 2.5 & 54.67 & 81.8 & 8.57 & 7.2 \\
\hline 3 & 55.88 & 83.6 & 10.98 & 9.56 \\
\hline 3.5 & 56.76 & 84.5 & 12.73 & 10.74 \\
\hline 4 & 57.99 & 86 & 15.17 & 2.71 \\
\hline
\end{tabular}

The compressive strength increased continuously with the increase in the fiber content. The increase in the strength is directly proportional to the fiber content. The maximum increase in compressive strength at $3.5 \%$ of fiber content is $10.74 \%$ at 28 days

\section{Conclusions}

The following conclusions are drawn from the test results and discussion of this investigation.

1. The compressive strength of concrete increase with increase in fiber content

2. The maximum increase in compressive strength at $4.0 \%$ of fiber content is $14.54 \%$ at 28 days in case of waving shape fiber

3. The maximum increase in compressive strength at $4.0 \%$ of fiber content is $15.72 \%$ at 28 days in case of flat shape fiber.

4. The maximum increase in compressive strength at $3.5 \%$ of fiber content is $10.74 \%$ at 28 days in case of hook shape fiber.

\section{References}

[1]. P. N. Balaguru, and S. P. Shah, 1992, Fiber Reinforced Cement Composites, McGraw-Hill: New York.

[2]. J. J. Beaudoin, 1990, Handbook of Fibre Reinforced Concrete - Principles, Developments and Applications, Noyes Publications: New Jersey, USA.

[3]. D. J. Hannant, 1978, Fibre Cements and Fibre Concretes, John Wiley and Sons: New York, USA

[4]. G. R. Williamson, 1974, The effect of steel fibres on compressive strength of concrete, ACI Special Publication. SP-44, 195-207.

[5]. S. P. Shah and V. B. Rangan, 1971, Fibre reinforced concrete properties, ACI Journal. 68, $126-135$.

[6]. C. D Johnston and R. A. Coleman, 1974, Strength and deformation of steel fibers reinforced Mortars in uniaxial tension, ACI SP-44, 177-193.

[7]. C. D. Johnston, 1984, Steel fibre reinforced mortar and concrete: A review of mechanical properties, ACI SP-44, 127-142.

[8]. R. N. Swamy, et al., 1974, The mechanics of fibre reinforcement in cement matrices: Fibrereinforced concrete, ACI SP-44, 1-28.

[9]. R. N. Swami and S. A. Al-Taan, 1981, Deformation and ultimate strength in flexure of reinforced concrete beam made with steel fibre concrete, ACI Journal, 78, 395-405.

[10]. M. A. Mansur, et al., 1986, Shear strength of fibrous concrete beams without stirrups, ASCE Journal of Structural Engineering. 112, 2068-2079.

[11]. ACI Committee 544 Report, 1988, Design of steel fibre reinforced concrete, ACI Structural Journal, 85, 563-580.

[12]. Y. M. Ghugal, 2003, Effects of steel fibers on various strengths of concrete, Indian Concrete Institute Journal. 4, $23-29$.

[13]. Y. M. Ghugal, 2006, Performance of alkali-resistant glass fibre reinforced concrete, Journal of Reinforced Plastics and Composites. 25, 617-630, SAGE Publications, USA.

[14]. ASTM Standard: C234-91a, Test for comparing concretes on the basis of the bond developed with reinforcing steel. ASTM Standards, Philadelphia, USA 